\title{
Advancing women in academic medicine: ten strategies to use every day
}

\author{
Anna Geagea, MD, FRCPC • Sangeeta Mehta, MD, FRCPC
}

Received: 24 April 2019/Revised: 2 July 2019/Accepted: 3 July 2019/Published online: 23 July 2019

(C) Canadian Anesthesiologists' Society 2019

Women are well represented in medical schools $^{1}$ and increasingly so in academic medicine. ${ }^{2}$ Nevertheless, there remains a significant gap in the representation of women as professors, ${ }^{3}$ as leaders, ${ }^{1,4}$ on guideline panels, ${ }^{5}$ as conference speakers and chairs, ${ }^{6,7}$ in scholarly publications, ${ }^{8}$ and as grant and award recipients. ${ }^{9,10}$ There is also a significant pay gap between men and women physicians. ${ }^{11}$ These gender disparities are particularly evident in disciplines such as critical care medicine and in surgical specialties. ${ }^{1,5,7}$

There are many reasons for gender disparity in medicine, including implicit bias that contributes to stereotypes that associate men with leadership, unequal mentorship and sponsorship, ${ }^{12}$ all added to the disproportionately greater familial responsibilities for women. ${ }^{13}$ Sexual and gender harassment of women faculty and trainees is widespread in medicine. ${ }^{14,15}$ All of these challenges may also result in lower retention of women in academia. ${ }^{16}$

We suggest ten ways that both men and women can support women faculty and trainees, ensure that women's voices are heard, and reduce the overall gender disparity in academic medicine.

A. Geagea, MD, FRCPC

Sunnybrook Health Sciences Centre, Toronto, ON, Canada

North York General Hospital, North York, ON, Canada

Interdepartmental Division of Critical Care Medicine, University of Toronto, Toronto, ON, Canada

S. Mehta, MD, FRCPC ( $₫)$

Interdepartmental Division of Critical Care Medicine, University of Toronto, Toronto, ON, Canada

e-mail: Geeta.mehta@utoronto.ca

Department of Medicine, Sinai Health System, 600 University Ave, Toronto, ON M5G 1X5, Canada
1. Be aware of your implicit bias and check your gender stereotypes

We all have implicit biases, which are unconscious prejudices towards a certain group of people. While implicit gender bias appears to be more prominent in older faculty and in men, ${ }^{17}$ both men and women hold stereotypical notions of how a woman physician looks and behaves. ${ }^{18}$ Identifying this implicit bias is especially important for leaders and educators. ${ }^{19}$ To evaluate your implicit biases, one can self-administer the Implicit Association Test (https://implicit.harvard.edu/) $)^{20}$; and consider implicit bias training. ${ }^{21}$

Stereotypical beliefs that revolve around women's intellectual capabilities, ambitions, personality traits, or work-life priorities can influence ones expectations and treatment of female colleagues. ${ }^{22}$ For example, one should not assume a woman is uninterested in an opportunity because she has young children. Indeed, in younger generations, men seek work-life integration as much as women. ${ }^{23,24}$ While statements such as "women are more compassionate than men" or "women are better communicators" may seem positive, such "benevolent sexism" sets expectations for women's behavior by reinforcing stereotypical beliefs. ${ }^{25}$ Unlike men, women face expectations of "communal" behavior, including likeability and nurturing, and are penalized for exhibiting "agentic" traits such as assertiveness. ${ }^{26}$ Consequently, women are assigned disproportionately more of the traditionally uncompensated responsibilities that may adversely impact their academic productivity. Ensure that committee membership, educational responsibilities, and social organizing (e.g., holiday parties) are assigned equally to women and men.

\section{Speak up about inequities}

Achieving gender equity is a collaborative venture. Regardless of your gender, talk to your colleagues about equity, speak up about unfairness and harassment, and advocate for transparency in hiring, compensation, and 
awards. Committees with broad and diverse representation may decrease inequalities in candidates' selection processes, and ensure that the most qualified and meritorious candidates are selected. If you witness gendered comments, simply stating "I'm not comfortable with what you said" calls out the perpetrator and validates the victim.

\section{Be a mentor}

Academic faculty who are mentored are more productive, ${ }^{27}$ have greater career advancement, ${ }^{28}$ and superior career satisfaction. ${ }^{29}$ While it is not evident that women are mentored less, women find it challenging to find a mentor that "fits it all" in terms of work-life integration. ${ }^{29}$ Consequently, women may be less satisfied than men with their mentorship experiences. ${ }^{29}$

As a potential mentor, seek opportunities to guide junior faculty, regardless of their sex. If you are a man, do not let the \#MeToo movement and fears of accusations about harassment prevent you from helping advance a woman's career. $^{30,31}$

\section{Be a sponsor}

Sponsorship_-distinct from mentoring-is defined as the promotion of a junior colleague by a more senior individual with influence and a network of connections. Sponsorship can increase visibility and is associated with success. ${ }^{32}$ Women are less likely to be sponsored than men, and less likely to benefit from the associated career advancement. ${ }^{32}$

If you are in a position of authority, introduce women to senior people in their scholarly areas, suggest women for committees, for panels, as conference and grand rounds speakers, and nominate women for leadership roles and awards.

\section{Ensure women's voices are heard, and use their professional titles}

Be generous about echoing women's suggestions, providing attribution, and crediting their viewpoints. "Amplification" is a strategy whereby women's comments are echoed by others, particularly when their voices have not been adequately heard or acknowledged. For example, within President Obama's office, amplification resulted in more women being invited to share their views and increased their contributions to policy-making. ${ }^{33}$

Women are interrupted far more often than men-even among supreme court judges! $!^{34}$ Refrain from interrupting women, unless it is primarily to gain clarity on her statements. If the interruption is to opine or to disagreepolitely wait your turn. Call out others who interrupt with "Why don't we let her finish her thoughts?"35
Women grand-rounds speakers are less likely than men to be introduced using their professional titles, and are more often introduced by their first names, particularly when introduced by a man. ${ }^{36}$ Withholding a professional's formal title has been associated with lower recognition of her expertise, lower satisfaction in the workplace, and feelings of alienation. ${ }^{36}$ Use formal professional titles for women and men in their work environments, particularly around trainees and patients. ${ }^{37}$

\section{Gender balance at conferences and scholarly activities-have a policy}

Despite the increasing presence of women in academia, they remain underrepresented as grand-rounds speakers, ${ }^{6}$ on the podium at professional conferences, ${ }^{7}$ as guideline panel members or authors, ${ }^{5,38}$ and on editorial boards. ${ }^{39,40}$ Formalized strategies which incorporate quotas improve gender equity.

If you are on a conference organizing committee, have an equity policy for panels, chairs, and speakers, and aim to achieve better gender balance. ${ }^{41}$ Recruit more women on the organizing committee, as this has been shown to improve speaker gender balance. ${ }^{42}$ Publish your gender data; if you fail to meet your quota, have a plan in place to address it.

Consider whether you wish to participate in genderimbalanced events; some invitees have politely declined to attend unless there is gender equity. To address the perception that women decline invitations more than men, collect data on declinations and their reasons. Consider providing onsite childcare and a family room to support attendance of those with family needs.

\section{Support women trainees}

Despite similar evaluations early in training, women emergency medicine trainees achieve milestones later than peer men, leading to a gender gap in evaluations. ${ }^{43}$ Other studies have reported lower evaluation scores for women anesthesia trainees during their critical care rotations $^{44}$; and inferior cardiopulmonary resuscitation performance in women. ${ }^{45}$ Failure to show stereotypical leadership characteristics may explain the perception of lower performance in women, particularly in specialties such as emergency medicine that expect traditionally maledefined behaviors (e.g., independence, assertiveness). ${ }^{43,45}$ Paradoxically, women who assume such leadership characteristics may be penalized for their behaviour. ${ }^{46,47}$ For both women and men trainees, anticipating and adhering to gendered behavioral expectations is stressful and distracts from clinical work. Hold both women and men trainees to the same performance standards and seek equitable and objective evaluation processes. 


\section{Avoid gendered letters of recommendation}

Stereotypical gender expectations impact women through gender-based descriptions of their performance in reference letters. Women applicants are less likely to be described as "bright" than men applicants, or to have their leadership potential addressed. They are also more likely to have physical appearance mentioned, particularly by referee men. ${ }^{48,49}$ Referees are more likely to describe women using communal terms such as compassionate, calm, and delightful. ${ }^{50}$ Avoid stereotypical adjectives when writing reference letters for women, and consider having a women colleague screen your letter.

\section{Ensure all scholarly activities are inclusive and safe}

Scholarly activities provide important opportunities for education and networking. Junior faculty with young children or those who are single parents may not be able to attend early morning or evening events. Since women generally have disproportionate childcare and eldercare responsibilities, and the partners of men physicians are less likely to work outside the home, this particularly excludes women. ${ }^{13}$ Ensure scholarly activities are inclusive and scheduled in a family-friendly manner to enable all faculty to attend, and avoid social activities which might be primarily attended by men. ${ }^{51}$ A code of conduct can help create a safe, harassment-free environment for women and men.

\section{Address the gender pay gap}

In the United States, women in academia earn less than their men counterparts. ${ }^{52}$ The pay gap results from multiple factors, including implicit gender bias, the perceived impact of familial leave on productivity, and less assertive negotiation by women. If you are in a position of authority, ensure transparency and standardization of compensation based on the job description and responsibilities. Including women and under-represented minorities on the economic committee may help reduce the pay gap. Offer negotiation skills training to all junior faculty. ${ }^{52}$

Including women in all academic activities enriches our community, and benefits everyone. Achieving gender equity is possible, but only if we all act as allies and champions of change. This means that both men and women need to support and elevate women, notice and call attention to inequities, and propose constructive solutions. These ten strategies can promote systemic change and the success of women in academia. The only way is forward!

Acknowledgement The authors would like to express their appreciation to Dr. Deborah Cook for her generous review of the manuscript.
Conflicts of interest None declared.

Editorial responsibility This submission was handled by Dr. Hilary P. Grocott, Editor-in-Chief, Canadian Journal of Anesthesia.

\section{References}

1. Association of American Medical Colleges. The State of Women in Academic Medicine: The Pipeline and Pathways to Leadership, 2015-2016. Available from URL: https://www. aamc.org/members/gwims/statistics/ (accessed July 2019).

2. Jagsi R, Guancial EA, Worobey CC, et al. The "gender gap" in authorship of academic medical literature-a 35-year perspective. N Engl J Med 2006; 355: 281-7.

3. Blumenthal DM, Olenski AR, Yeh RW, et al. Sex differences in faculty rank among academic cardiologists in the United States. Circulation 2017; 135: 506-17.

4. Silver JK, Ghalib R, Poorman JA, et al. Analysis of gender equity in leadership of physician-focused medical specialty societies, 2008-2017. JAMA Intern Med 2019. DOI: https://doi.org/10. 1001/jamainternmed.2018.5303.

5. Mehta S, Burns KE, Machado FR, et al. Gender parity in critical care medicine. Am J Respir Crit Care Med 2017; 196: 425-9.

6. Buell D, Hemmelgarn BR, Straus SE. Proportion of women presenters at medical grand rounds at major academic centres in Canada: a retrospective observational study. BMJ Open 2018. DOI: https://doi.org/10.1136/bmjopen-2017-019796.

7. Mehta $S$, Rose L, Cook D, Herridge M, Owais $S$, Metaxa V. The speaker gender gap at critical care conferences. Crit Care Med 2018; 46: 991-6.

8. Raj A, Carr PL, Kaplan SE, Terrin N, Breeze JL, Freund KM. Longitudinal analysis of gender differences in academic productivity among medical faculty across 24 medical schools in the United States. Acad Med 2016; 91: 1074-9.

9. Kaatz A, Lee YG, Potvien A, et al. Analysis of National Institutes of Health R01 application critiques, impact, and criteria scores: does the sex of the principal investigator make a difference? Acad Med 2016; 91: 1080-8.

10. Ellinas EH, Rebello E, Chandrabose RK, Shillcutt SK, Hernandez $M$, Silver $J K$. Distinguished service awards in anesthesiology specialty societies: analysis of gender differences. Anesth Analg 2019. DOI: https://doi.org/10.1213/ane.0000000000004132.

11. Jena AB, Olenski AR, Blumenthal DM. Sex differences in physician salary in US public medical schools. JAMA Intern Med 2016; 176: 1294-304.

12. Carr PL, Szalacha L, Barnett R, Caswell C, Inui T. A "ton of feathers": gender discrimination in academic medical careers and how to manage it. J Womens Health (Larchmt) 2003; 12: 100918.

13. Jolly $S$, Griffith KA, DeCastro R, Stewart A, Ubel P, Jagsi R. Gender differences in time spent on parenting and domestic responsibilities by high-achieving young physician-researchers. Ann Intern Med 2014; 160: 344-53.

14. Jagsi R, Griffith KA, Jones R, Perumalswami CR, Ubel P, Stewart $A$. Sexual harassment and discrimination experiences of academic medical faculty. JAMA 2016; 315: 2120-1.

15. Fnais $N$, Soobiah $C$, Chen $M H$, et al. Harassment and discrimination in medical training: a systematic review and meta-analysis. Acad Med 2014; 89: 817-27.

16. Shen $H$. Inequality quantified: mind the gender gap. Nature 2013; 495: 22-4. 
17. Girod S, Fassiotto M, Grewal D, et al. Reducing implicit gender leadership bias in academic medicine with an educational intervention. Acad Med 2016; 91: 1143-50.

18. Cooke M. Implicit bias in academic medicine: \#whatadoctorlookslike. JAMA Intern Med 2017; 177: 657-8.

19. Corrice A. Unconscious bias in faculty and leadership recruitment: a literature review. Association of American Medical Colleges; Analysis in Brief. 2009, volume 9, number 2. Available from URL: https://www.aamc.org/download/ 102364/data/aibvol9no2.pdf (accessed July 2019).

20. Greenwald AG, McGhee DE, Schwartz JL. Measuring individual differences in implicit cognition: the implicit association test. J Pers Soc Psychol 1998; 74: 1464-80.

21. Association of American Medical Colleges. Unconscious Bias Resources for the Health Professions. Available from URL: https://www.aamc.org/initiatives/diversity/322996/lablearningon unconsciousbias.html (accessed July 2019).

22. Correll $S$. Reducing gender biases in modern workplaces: a small wins approach to organizational change. Gender \& Society 2017; 31: 725-50.

23. Lambert EM, Holmboe ES. The relationship between specialty choice and gender of U.S. medical students, 1990-2003. Acad Med 2005; 80: 797-802.

24. Ecklund EH, Lincoln AE. Scientists want more children. PLoS One 2011. DOI: https://doi.org/10.1371/journal.pone.0022590.

25. Kristoffersson E, Andersson J, Bengs C, Hamberg K. Experiences of the gender climate in clinical training - a focus group study among Swedish medical students. BMC Med Educ 2016. DOI: https://doi.org/10.1186/s12909-016-0803-1.

26. Carnes M, Bartels CM, Kaatz A, Kolehmainen C. Why is John more likely to become department chair than Jennifer? Trans Am Clin Climatol Assoc 2015; 126: 197-214.

27. Reid MB, Misky GJ, Harrison RA, Sharpe B, Auerbach A, Glasheen JJ. Mentorship, productivity, and promotion among academic hospitalists. J Gen Intern Med 2012; 27: 23-7.

28. Beasley $B W$, Simon SD, Wright SM. A time to be promoted. The prospective study of promotion in academia (Prospective Study of Promotion in Academia). J Gen Intern Med 2006; 21: 123-9.

29. DeCastro R, Griffith KA, Ubel PA, Stewart A, Jagsi R. Mentoring and the career satisfaction of male and female academic medical faculty. Acad Med 2014; 89: 301-11.

30. Byerley JS. Mentoring in the era of \#MeToo. JAMA 2018; 319: 1199-200.

31. Soklaridis S, Zahn C, Kuper A, Gillis D, Taylor VH, Whitehead C. Men's fear of mentoring in the \#MeToo era - what's at stake for academic medicine? N Engl J Med 2018; 379: 2270-4.

32. Patton EW, Griffith KA, Jones RD, Stewart A, Ubel PA, Jagsi R. Differences in mentor-mentee sponsorship in male vs female recipients of National Institutes of Health grants. JAMA Intern Med 2017; 177: 580-2.

33. Beck-Esmay K. "Amplification" - a strategy for empowering our voices. December 2016. Available from URL: https://feminem.org/ 2016/12/15/amplification-strategy-empowering-voices/?platform= hootsuite (accessed July 2019).

34. Jacobi T, Schweers D. Justice, interrupted: the effect of gender, ideology and seniority at Supreme Court oral arguments. Virginia Law Review Association 2017; 103: 1379-496.

35. Shore L. Gal interrupted, why men interrupt women and how to avert this in the workplace. January 03, 2017. Available from URL: https://www.forbes.com/sites/womensmedia/2017/01/03/ gal-interrupted-why-men-interrupt-women-and-how-to-avert-thisin-the-workplace/-f11752f17c38 (accessed July 2019).
36. Files JA, Mayer AP, Ko $M G$, et al. Speaker introductions at internal medicine grand rounds: forms of address reveal gender bias. J Womens Health (Larchmt) 2017; 26: 413-9.

37. Devon KM. Call me by my name: doctor. Ann Surg 2019; 270 : 29-30.

38. Merman E, Pincus D, Bell C, et al. Differences in clinical practice guideline authorship by gender. Lancet 2018; 392: 16268.

39. Khan $Y$, Ali A, Bell C, Ratan D, Datt S, Mehta S. Women, visible minorities and residents of lower-middle income countries are underrepresented in leading respirology and critical care journals. Am J Respir Crit Care Med 2019; 199: A4167 (abstract).

40. Lorello GR, Parmar A, Flexman AM. Representation of women on the editorial board of the Canadian Journal of Anesthesia: a retrospective analysis from 1954 to 2018. Can J Anesth 2019. DOI: https://doi.org/10.1007/s12630-019-01378-9.

41. Martin JL. Ten simple rules to achieve conference speaker gender balance. PLoS Comput Biol 2014. DOI: https://doi.org/10.1371/ journal.pcbi.1003903.

42. Casadevall A, Handelsman J. The presence of female conveners correlates with a higher proportion of female speakers at scientific symposia. MBio 2014; 5: e00846-13.

43. Dayal A, O'Connor DM, Qadri U, Arora VM. Comparison of male vs female resident milestone evaluations by faculty during emergency medicine residency training. JAMA Intern Med 2017; 177: 651-7.

44. Spring J, Abrahams C, Ginsburg S, Piquette D, Kiss A, Mehta S. The impact of gender on clinical evaluation of trainees in the intensive care unit. Am J Respir Crit Care Med 2019; 199: A4165 (abstract)

45. Amacher SA, Schumacher C, Legeret $C$, et al. Influence of gender on the performance of cardiopulmonary rescue teams: a randomized, prospective simulator study. Crit Care Med 2017; 45: 1184-91.

46. Kolehmainen $C$, Brennan $M$, Filut A, Isaac C, Carnes $M$. Afraid of being "witchy with a 'b" : a qualitative study of how gender influences residents' experiences leading cardiopulmonary resuscitation. Acad Med 2014; 89: 1276-81.

47. Heilman ME, Wallen AS, Fuchs D, Tamkins MM. Penalties for success: reactions to women who succeed at male gender-typed tasks. J Appl Psychol 2004; 89: 416-27.

48. Friedman R, Fang CH, Hasbun J, et al. Use of standardized letters of recommendation for otolaryngology head and neck surgery residency and the impact of gender. Laryngoscope 2017; 127: 2738-45.

49. Messner AH, Shimahara E. Letters of recommendation to an otolaryngology/head and neck surgery residency program: their function and the role of gender. Laryngoscope 2008; 118: 133544.

50. Hoffman A, Grant W, McCormick M, Jezewski E, Matemavi P, Langnas A. Gendered differences in letters of recommendation for transplant surgery fellowship applicants. J Surg Educ 2019; 76: 427-32.

51. Colletti LM, Mulholland MW, Sonnad SS. Perceived obstacles to career success for women in academic surgery. Arch Surg 2000; 135: $972-7$.

52. Freund KM, Raj A, Kaplan SE, et al. Inequities in academic compensation by gender: a follow-up to the National Faculty Survey Cohort Study. Acad Med 2016; 91: 1068-73.

Publisher's Note Springer Nature remains neutral with regard to jurisdictional claims in published maps and institutional affiliations. 